\title{
Major HGF-mediated regenerative pathways are similarly affected in human and canine cirrhosis
}

\author{
Bart Spee $^{\dagger 1,2}$, Brigitte Arends ${ }^{\dagger 1}$, Ted SGAM van den Ingh ${ }^{1}$, Tania Roskams², \\ Jan Rothuizen ${ }^{1}$ and Louis C Penning*1
}

\begin{abstract}
Address: ${ }^{1}$ Department of Clinical Sciences of Companion Animals, Faculty of Veterinary Medicine, Utrecht University, The Netherlands and ${ }^{2}$ Department of Morphology and Molecular Pathology, University Hospitals Leuven, Belgium

Email: Bart Spee - B.Spee@vet.uu.nl; Brigitte Arends - B.Arends@vet.uu.nl; Ted SGAM van den Ingh - t.s.g.a.m.vandeningh@wanadoo.nl; Tania Roskams - tania.roskams@uz.kuleuven.ac.be; Jan Rothuizen - J.Rothuizen@vet.uu.nl; Louis C Penning* - L.C.Penning@vet.uu.nl

* Corresponding author †Equal contributors
\end{abstract}

Published: 3I July 2007

Comparative Hepatology 2007, 6:8 doi:10.1 186/1476-5926-6-8
Received: 19 December 2006

Accepted: 3I July 2007

This article is available from: http://www.comparative-hepatology.com/content/6/1/8

(C) 2007 Spee et al; licensee BioMed Central Ltd.

This is an Open Access article distributed under the terms of the Creative Commons Attribution License (http://creativecommons.org/licenses/by/2.0), which permits unrestricted use, distribution, and reproduction in any medium, provided the original work is properly cited.

\begin{abstract}
Background: The availability of non-rodent animal models for human cirrhosis is limited. We investigated whether privately-owned dogs (Canis familiaris) are potential model animals for liver disease focusing on regenerative pathways. Several forms of canine hepatitis were examined: Acute Hepatitis (AH), Chronic Hepatitis (CH), Lobular Dissecting Hepatitis (LDH, a specific form of micronodulair cirrhosis), and Cirrhosis (CIRR). Canine cirrhotic samples were compared to human liver samples from cirrhotic stages of alcoholic liver disease (hALC) and chronic hepatitis C infection (hHC).

Results: Canine specific mRNA expression of the regenerative hepatocyte growth factor (HGF) signaling pathway and relevant down-stream pathways were measured by semi-quantitative PCR and Western blot (STAT3, PKB, ERKI/2, and P38-MAPK). In all canine groups, levels of c-MET mRNA (proto-oncogenic receptor for HGF) were significantly decreased $(p<0.05)$. Surprisingly, ERKI/2 and p38-MAPK were increased in CH and LDH. In the human liver samples Western blotting indicated a high homology of down-stream pathways between different etiologies (hALC and hHC). Similarly activated pathways were found in CIRR, hALC, and hHC.

Conclusion: In canine hepatitis and cirrhosis the major regenerative downstream pathways were activated. Signaling pathways are similarly activated in human cirrhotic liver samples, irrespective of the differences in etiology in the human samples (alcohol abuse and HCV-infection). Therefore, canine hepatitis and cirrhosis could be an important clinical model to evaluate novel interventions prior to human clinical trials.
\end{abstract}

\section{Background}

Chronic hepatitis $(\mathrm{CH})$ and end-stage cirrhosis (CIRR) are an increasing medical problem, affecting over $5 \%$ of the world population $[1,2]$. The best-studied animal model for these liver diseases is tetracarbon-induced fibrotic liver diseases inflicted in rats [3]. Many more models have been devised to mimic liver diseases in man; the time-course of the development however, is not always comparable to the human situation [4-8]. Furthermore, the variability in the affected human population regarding, sex, age, social 
factors, eating- and drinking behavior, body weight etc. is not fully covered in standardized laboratory conditions.

Dogs have liver diseases which are clinically highly comparable with the human counterparts and both species have a high resemblance at the genetic level $[9,10]$. In contrast to rodent models, hepatitis in these dogs is not deliberately induced. Previous studies already showed a high resemblance between man and dogs in the formation of fibrosis during liver diseases [11]. Furthermore dogs share many years in close proximity of humans exposing them to the same environmental and biological stresses. Recently, detailed clinical and histological diagnostic standards have been published for all liver diseases of dogs [12]. Corroborating the histological similarities between human and dogs, examples are provided in Figure 1 . Taken together, these similarities suggest the dog as a model animal for liver diseases in man [13].

Liver regeneration is a complex interplay of different factors [14]. One of the main growth factors identified in liver regeneration is Hepatocyte Growth Factor (HGF). HGF activates the proto-oncogenic receptor tyrosine kinase c-MET and subsequent down-stream pathways, including the anti-apoptotic protein kinase- $\mathrm{B}$ (PKB/Akt) cascade, the proliferative MAP-kinase pathway (ERK1/2 and p38MAPK), and the STAT3 signaling (signal transducers and activators of transcription) [15-17]. At present, a comparison between these regeneration signal transduction pathways in human and canine livers is missing, hampering the application of dogs as (pre-) clinical model animals for human medicine.

We have analyzed HGF-mediated regeneration signaling in canine samples from dogs with Acute Hepatitis (AH), Chronic Hepatitis (CH), and Lobular Dissecting Hepatitis (LDH, a specific form of micronodulair cirrhosis similar to neonatal hepatitis in human hepatology) $[18,19]$, and CIRR. The cirrhotic samples were compared to two human cirrhotic diseases with different etiologies; HCVinduced (hHC) and alcohol-induced (hALC). This study will elucidate the potential of (non-experimental) dogs to bridge between toxin-induced rodent models and human clinical situation.

\section{Results}

\section{HGF/c-MET signaling pathways involved in liver} regeneration in dogs with $A H, C H, C I R R$, and $L D H$

Statistically significant differences (ANOVA) were identified in the expression of mRNA encoding HGF $(P<.001)$ and c-MET $(P<.001)$. Towards healthy control samples HGF mRNA levels were significantly induced in $\mathrm{CH}, \mathrm{LDH}$, and CIRR, three-, five-, and five-fold, respectively (Figure 2A). In AH, HGF mRNA levels remained unchanged toward healthy control. Western blot analysis on HGF
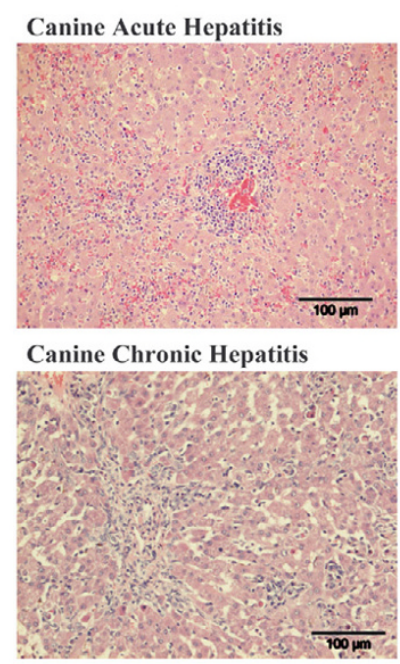

Canine Lobular Dissecting Hepatitis

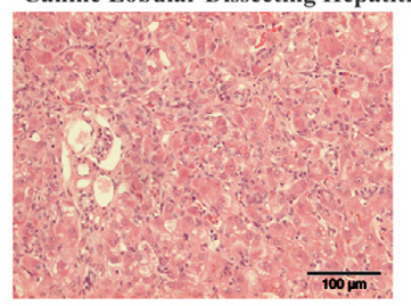

Canine Cirrhosis

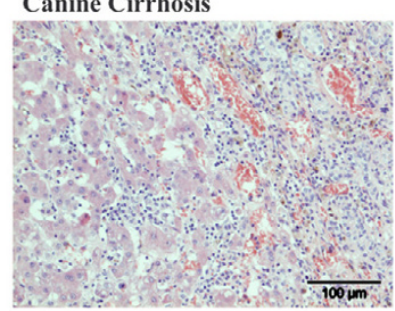

Figure I

Examples of histological samples (HE) from canine and human liver diseases. CANINE ACUTE HEPATITIS: Marked infiltration of mononuclear and granulocytic inflammatory cells and focal necrosis. CANINE CHRONIC HEPATITIS: Small fibrous septum with interface hepatitis as well as lobular hepatitis; several apoptotic bodies. CANINE LOBULAR DISSECTING HEPATITIS: Lobular dissection by fibroblasts and ductular proliferation and a slight inflammatory infiltrate. CANINE CIRRHOSIS: Broad fibrous septum with ductular proliferation and a marked inflammatory infiltrate with interface hepatitis. HUMAN ACUTE HEPATITIS: Marked infiltration of mononuclear and some granulocytic inflammatory cells and some apoptotic bodies. HUMAN CHRONIC HEPATITIS: Fibrous septum with some ductular proliferation and slight interface hepatitis. HUMAN MICRONODULAR CIRRHOSIS: Dissection of the parenchyma by small fibrous septa, slight ductular proliferation and inflammation; hepatocytic ballooning, Mallory bodies, and apoptosis. HUMAN CIRRHOSIS: Broad fibrous septum with ductular proliferation and a marked inflammatory infiltrate with interface hepatitis. 
protein showed the presence of a HGF band $(80 \mathrm{kDa})$ in all canine samples. There is a clear quantitative correlation between HGF protein and mRNA levels, as both HGF mRNA and protein levels are increased in $\mathrm{CH}, \mathrm{LDH}$, and CIRR. The c-MET mRNA levels in all groups were significantly decreased towards control, with a maximum fourfold reduction in AH (Figure 2B). Total c-MET protein levels are similarly reduced as the mRNA levels. Analysis on phosphorylated c-MET showed an immuno-reactive band in $\mathrm{CH}, \mathrm{LDH}$, and CIRR, which was almost absent in $\mathrm{AH}$.

\section{Western blot analysis on STAT3, PKB/Akt, ERKI/2, and p38MAPK in canine liver homogenates}

In Figure 3 important downstream signaling proteins of HGF/c-MET (STAT3, PKB/Akt, ERK1/2, and p38-MAPK) are depicted. The total STAT3 was detected as an immunoreactive $86 \mathrm{kDa}$ band in all hepatic diseases, with slightly lower expression in $\mathrm{CH}, \mathrm{LDH}$, and CIRR. Tyrosine (Tyr)phosphorylated STAT3 was strongly reduced in AH and was increased in LDH. Healthy controls, $\mathrm{CH}$, and CIRR groups had comparable levels of Tyr-phosphorylated STAT3. Serine (Ser)-phosphorylated STAT3 was slightly decreased in CIRR. PKB/Akt plays a pivotal role during regeneration and growth. Total $\mathrm{PKB} / \mathrm{Akt}$ was detected in all hepatic diseases as a single $60 \mathrm{kDa}$ protein. Threonine (Thr)-phosphorylated PKB/Akt was less present in AH and CIRR, whereas $\mathrm{CH}$ and LDH showed no apparent quantitative differences toward healthy controls. Analysis of total ERK1/2 (42/44 kDa), a principle kinase in growth factor signaling, showed a slight reduction in $\mathrm{AH}$, and moderate increases in $\mathrm{CH}, \mathrm{LDH}$, and CIRR. The phosphorylated form threonine/tyrosine (Thr/Tyr)-phosphorylated ERK1/2 was strongly increased in $\mathrm{CH}$ and $\mathrm{LDH}$. A similar effect can be seen in p38-MAPK, an increased expression of total p38-MAPK in $\mathrm{CH}, \mathrm{LDH}$, and CIRR and decreased levels in AH. The threonine/tyrosine (Thr/Tyr)phosphorylated p38-MAPK form is increased in $\mathrm{CH}, \mathrm{LDH}$, and CIRR.

\section{Western blot analysis on human cirrhotic explant samples after alcohol abuse (hALC) and after hepatitis $C$ virus infection (hHC)}

Western blot analysis on HGF in hALC and hHC samples showed a detectable $80 \mathrm{kDa}$ HGF in all samples with minor quantitative differences (Figure 4). The $145 \mathrm{kDa}$ MET was also detected in all samples. The phosphorylated form of c-MET (Tyr) was detected in all samples. Total $\mathrm{PKB} /$ Akt was detected in all samples. The phosphorylated PKB (Thr) indicated moderate to high levels in most cirrhotic samples. Total STAT3 was detectable in all individual samples. STAT3 (Tyr) was detected in all groups although two samples in the hHC group were less phosphorylated. In general the serine phosphorylated STAT3 is lower in the hALC group compared to the hHC group. Total ERK1/2 was detected in all samples with no appar-
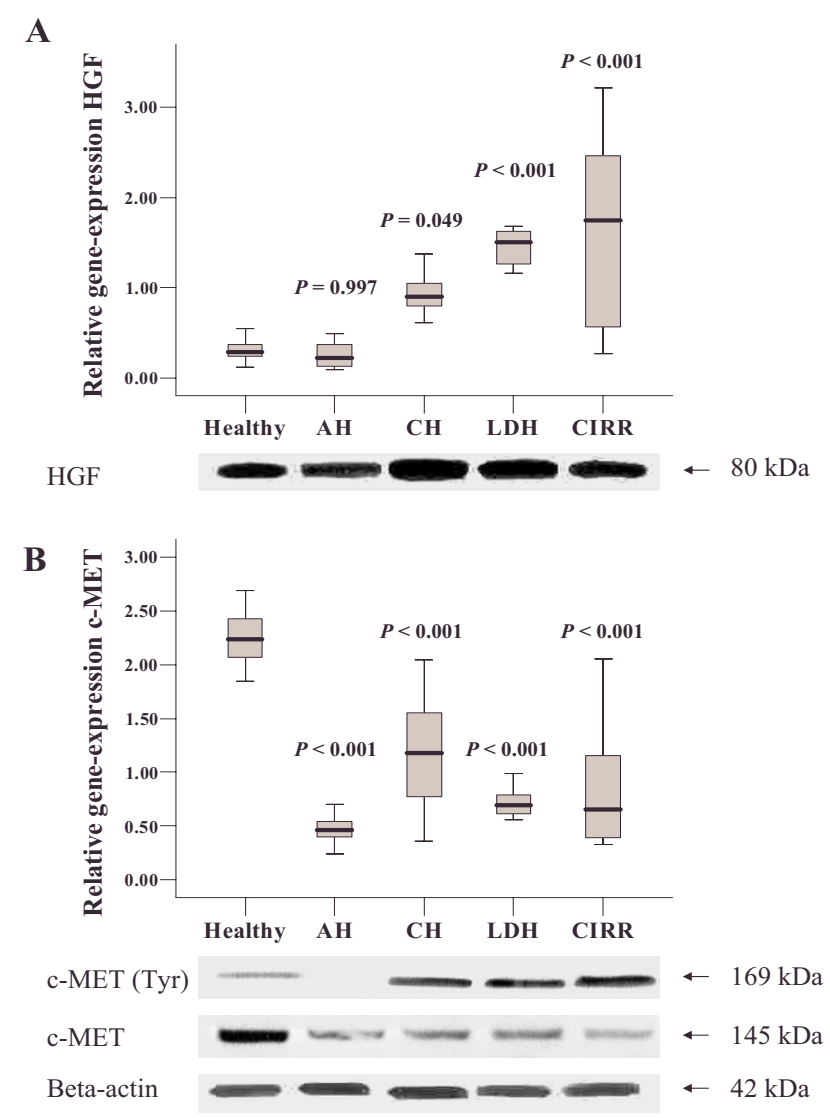

Figure 2

Quantitative Real-Time PCR of genes involved in regeneration and growth. Expression analysis of acute hepatitis $(\mathrm{AH})$, chronic hepatitis $(\mathrm{CH})$, lobular dissecting hepatitis (LDH), cirrhotic samples (CIRR). HGF expression and detection of the $80 \mathrm{kDa}$ HGF protein is shown in (A). c-MET gene expression and detection of c-MET including phosphorylated (Tyr) form is shown in (B). Relative gene expression data represent mean + SE. A Kolmogorov-Smirnov test was performed to establish a normal distribution and a Levenes test for the homogeneity of variances. All samples included in this study were normally distributed. The statistical significance of differences between diseased and control animals was determined by using the two-sided Dunnetts post-test analysis. A P-value $<0.05$ was considered statistically significant. Analysis was performed using SPSS software (SPSS Benelux BV, Gorinchem, the Netherlands).

ent quantitative differences. Phosphorylated ERK1/2 was detectable in all samples with different degrees of phosphorylation. Both total p38MAPK as well as the serine phosphorylated form was detected in all samples with no apparent quantitative differences.

\section{Discussion}

To investigate if hepatic regenerative signal transduction pathways are similarly affected in liver diseases between 


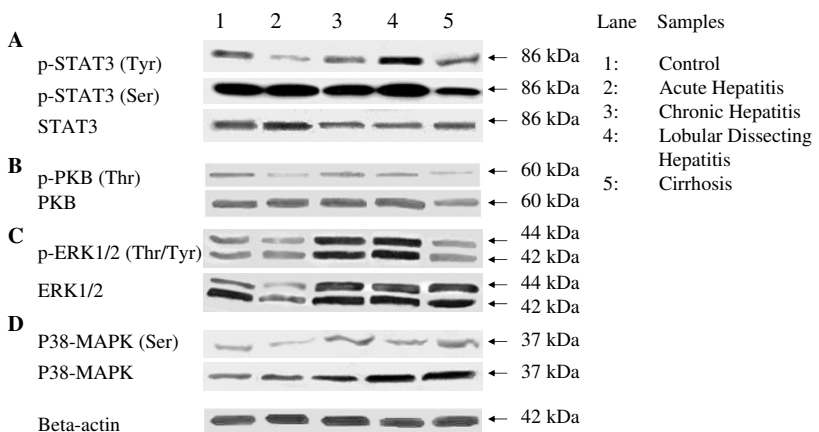

Figure 3

Western blot analysis of canine liver homogenates of several diseases $(n=6)$. Western blot analysis of pooled canine liver homogenates in acute hepatitis $(\mathrm{AH})$, chronic hepatitis $(\mathrm{CH})$, lobular dissecting hepatitis (LDH), cirrhotic samples (CIRR). Detection of the $86 \mathrm{kDa}$ STAT3 protein (A), detection of the $60 \mathrm{kDa}$ PKB protein (B), detection of the 44/ $42 \mathrm{kDa}$ ERK I/2 protein shown in (C), and detection of the p38-MAPK protein shown in (D). Beta-actin was used as a loading control.

man and dogs, the expression of HGF and c-MET was measured. Furthermore, Western blot analysis was used to show (de)activation of important signaling pathways of liver regeneration. This provided insight into major regeneration pathways in $\mathrm{AH}, \mathrm{CH}, \mathrm{LDH}, \mathrm{CIRR}$. A comparison between canine cirrhosis and human cirrhotic samples with different etiologies provided additional information on the suitability of the canine-model.

The increased mRNA levels of HGF and the decreased levels of c-MET mRNA in fibrotic canine diseases $(\mathrm{CH}, \mathrm{LDH}$, and CIRR), were in line with publications from human samples [20]. Together this suggests that HGF-mediated regeneration in human cirrhosis is similarly affected in canine $\mathrm{CH}, \mathrm{LDH}$, and CIRR. The reduced c-MET protein levels indicate a utilization of c-MET which is degraded through endocytosis after phosphorylation. Intracellular degradation is dependent on the interaction with $\mathrm{Cbl}$ ubiquitin ligases [21]. Semi-quantitative hepatocyte proliferation studies on canine samples with a Ki67 antibody indicate a moderate hepatocyte proliferation in $\mathrm{CH}$; whereas cirrhotic samples (CIRR and LDH) as well as healthy samples are virtually negative (data not shown). Similar results have been described in human chronic and cirrhotic liver samples, irrespective of the etiology $[22,23]$. This indicates the ability of hepatocytes to proliferate after c-MET activation in more chronic stages while cirrhotic samples do not complete the cell-cycle of which the cause remains to be elucidated.

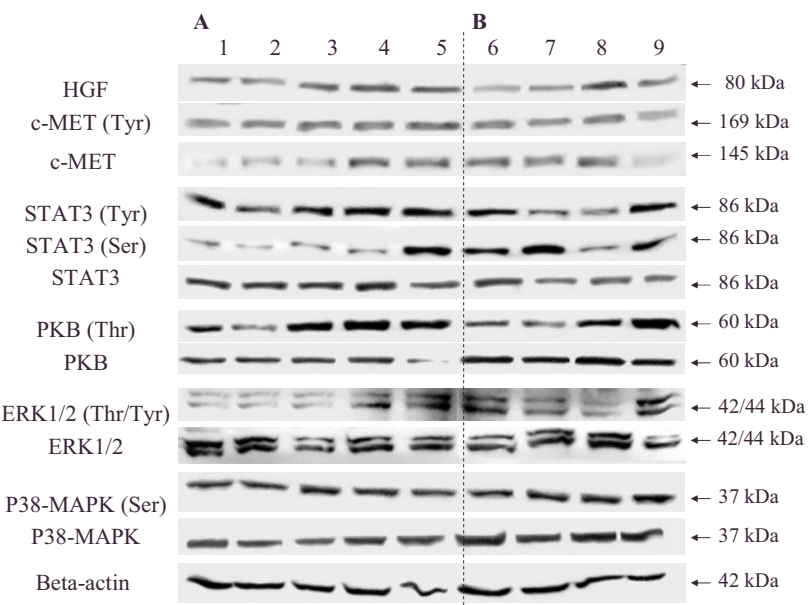

Figure 4

Western blot analysis of human liver homogenates of several diseases $(\mathbf{n}=\mathbf{6})$. Samples I to 5 represent individual alcoholic cirrhosis (hALC) shown in (A), samples 6 to 9 represent individual hepatitis $C$ induced cirrhotic samples (hHC) shown in (B). Beta-actin was used as a loading control.

To further substantiate the molecular comparison between human and canine fibrotic livers the activation status of HGF/c-MET downstream signaling components involved in regeneration was analyzed. HCV cirrhotic samples had high levels of Ser-phosphorylated STAT3 compared to alcohol induced cirrhotic samples. This HCV-induced up regulation of STAT3 phosphorylation was shown before in man and rodent models in vivo as well as in vitro studies on cell-lines [24,25]. In other studies the levels of STAT phosphorylation indicated phosphorylated STAT3 protein in HCV affected cirrhotic livers compared to primary biliary cirrhotic samples and healthy tissue [26]. In the canine samples including the healthy control biopsies STAT3-Ser phosphorylation was strongly present. The levels of STAT3-Tyr phosphorylation were the lowest in $\mathrm{AH}$ and strongest in $\mathrm{LDH}$. As the amount of STAT3-Tyr phosphorylation indicates the DNA binding capacity of the protein, the pathways seems to be activated in fibrotic diseases and not in acute hepatitis.

Next to STAT3 phosphorylation, HCV induces ERK1/2 phosphorylation [27]. In the canine samples, an up regulation of the levels of phosphorylated ERK1/2 was observed in $\mathrm{CH}$ and LDH. Finally, the increase in p38MAPK phosphorylation as observed in $\mathrm{CH}, \mathrm{LDH}$, and CIRR has been described in fibrotic tissues in man [28]. In general, $\mathrm{HGF} / \mathrm{c}-\mathrm{MET}$ downstream signaling in $\mathrm{CH}, \mathrm{LDH}$, and CIRR is to a high degree comparable with the molecular data obtained from human clinical samples. 
Surgical animal models for liver regeneration, such as partial hepatectomy $(\mathrm{PH})$, represent an over-simplification by the absence of inflammation or overperfusion; furthermore, all hepatocytes are stimulated by PH to enter the G1 phase simultaneously. Toxic models induced by dimethylnitrosamine, $\mathrm{CCl}_{4}$, acetominophen, or thioacetamide can represent chronic as well as acute/fulminant hepatitis [29-31]. Toxic models are better clinical models as hepatotoxins can be used to selectively induce centrolobular and periportal necrotic lesions and thus mimic clinical liver diseases. However, toxin-induced models do not represent the full range of changes seen in human liver diseases [32].

Comparison between canine and human diseases was obtained by using cirrhotic human samples derived from alcohol abuse or hepatitis $\mathrm{C}$ infection, two of the most common causes of hepatitis in the Western world $[33,34]$. As in humans, chronic hepatitis in dogs is associated with progressive fibrosis, reduction in liver size and regeneration, and finally disruption of the liver architecture (cirrhosis), which may cause portal hypertension, ascites, and portosystemic encephalopathy [35]. Although histologically highly comparable to their human counterparts, the etiology of canine hepatitis is largely unknown [36]. However, human samples (hALC and hHC) showed the same degree of activation in the signal transduction pathways, irrespective of the different underlying etiology. Therefore, despite unknown etiology in dogs the underlying mechanisms are similarly activated.

\section{Conclusion}

This study is the first to measure expression profiles of crucial pathways of liver regeneration in canine liver diseases in comparison with man. Previously, a high similarity of affected fibrotic pathways between human- and canineliver diseases was found [11]. Combining these measurements on fibrotic- and regenerative-signaling pathways, privately owned dogs may help to fill in the gap between toxin-induced rodent models and human diseases. Furthermore, this study provides the basis to analyze more acute forms of hepatitis such as (sub)acute hepatitis in dog. Taken together, these results indicated that $\mathrm{CH}, \mathrm{LDH}$, and CIRR are suitable spontaneous large animal models to evaluate the clinical application of therapies such as cell transplantation or the administration of growth factors.

\section{Methods \\ Animals}

All samples were obtained from privately owned canines of different breeds referred to our veterinary clinic. All procedures were approved by Utrecht University's Ethical Committee, as required under Dutch legislation. Each disease group ( $n=11$ dogs) was compared to age-matched healthy control dogs $(\mathrm{n}=12)$, without clinical signs of hepatitis or other disease (histopathology did not reveal any abnormalities). Liver biopsies were obtained (ultrasound-guided) from all dogs under local anesthesia with a true cut $14 \mathrm{G}$ biopsy needle, preceded by ultrasonographic evaluation of the liver to exclude non-homogeneous hepatic changes. Two formalin-fixed biopsies were embedded in paraffin, sliced, and stained with hematoxylin and eosin-, van Gieson-, and reticulin-stain according to Gordon and Sweet. All histological examinations were performed by one experienced, certified veterinary pathologist. Two other biopsies were snap-frozen and stored at $70^{\circ} \mathrm{C}$ until molecular analysis.

\section{Human patients}

All liver samples were obtained from surgical patients transplanted at the Department of Abdominal Transplantation in the University Hospital Leuven, Leuven, Belgium. The procedures were approved by Leuven University's Ethical Committee, as required under Belgian legislation. Human explant samples were collected directly after surgery and immediately snap-frozen. All patients, predominantly male, were presented with micronodular cirrhosis. The Alcoholic Cirrhosis (hALC) group contained five patients $(n=5)$ characterized by cirrhosis with neutrophil infiltrations, alcohol related morphological changes (hepatocyte ballooning, Mallory bodies, necrosis), and in some cases steatosis and increased iron deposition. The Hepatitis $\mathrm{C}$ (hHC) group contained four patients $(n=4)$ characterized by cirrhosis with neutrophil infiltrations, lymphoid follicles and aggregates. All cases were presented with hepatocyte decay, apoptosis/necrosis, regeneration, and fibrosis.

\section{Quantitative PCR}

Quantitative real-time PCR (Q-PCR) was performed on HGF and c-MET. The abundance of mRNA was determined by reverse transcription followed by real-time quantitative PCR using appropriate primers (Table 1), as described previously [37]. For each experimental sample, two endogenous reference genes (GAPDH and HPRT) were included. The use of two reference genes is sufficient for reliable data [38]. Results were normalized according to the average amount of the endogenous references. The relative gene-expression of each gene-product was used as the basis for all comparisons. The results were assessed for normality and homogeneity of variances using, respectively, the Kolmogorov Smirnoff and the Levene tests. The data were normally distributed and variances complied; therefore differences between means were determined by One Way Analysis of Variance (ANOVA) followed by the (2-sided) Dunnett post-test analysis of all groups towards control (healthy) samples. A $P$-value $<0.05$ indicated significant changes. 
Table I: Nucleotide Sequences of Dog-Specific Primers for Real-Time Quantitative PCR

\begin{tabular}{|c|c|c|c|c|c|}
\hline Gene & Primer & Sequence (5'-3') & $\operatorname{Tm}\left({ }^{\circ} \mathrm{C}\right)$ & Product size (bp) & Accession number \\
\hline \multirow[t]{2}{*}{ GAPDH } & Forward & TGT CCC CAC CCC CAA TGT ATC & 58 & 100 & $\underline{A B 038240}$ \\
\hline & Reversed & CTC CGA TGC CTG CTT CAC TAC CTT & & & \\
\hline \multirow{2}{*}{ HPRT } & Forward & AGC TTG CTG GTG AAA AGG AC & 56 & 100 & $\underline{\mathrm{L} 77488 / /}$ \\
\hline & Reversed & TTA TAG TCA AGG GCA TAT CC & & & $\overline{\mathrm{L} 77489}$ \\
\hline \multirow[t]{2}{*}{ HGF } & Forward & AAA GGA GAT GAG AAA CGC AAA CAG & 58 & 92 & BDI05535 \\
\hline & Reversed & GGC CTA GCA AGC TTC AGT AAT ACC & & & \\
\hline \multirow[t]{2}{*}{ c-MET } & Forward & TGT GCT GTG AAA TCC CTG AAT AGA AATC & 59 & 112 & $\underline{A B I 18945}$ \\
\hline & Reversed & CCA AGA GTG AGA GTA CGT TTG GAT GAC & & & \\
\hline
\end{tabular}

\section{Immunoblot analysis}

Twenty micrograms of pooled protein extracts $(n=6$ dogs per group, randomly chosen) was separated by SDSPAGE, and transferred to a Hybond ECL nitrocellulose membrane (Amersham-Biosciences, Cleveland, $\mathrm{OH}$ ). The procedure for immunodetection was based on an ECLWestern blot analysis system, as previously described [39]. Primary antibodies are depicted in Table 2. Densitometric analysis was performed with a Geldoc2000 system with QuantityOne 4.3.0 software (Biorad). Human samples (protein load twenty micrograms) were analyzed separately; the immunoblot analysis was the same as for the dog protein extracts.

\section{Abbreviations}

AH - Acute Hepatitis; CH - Chronic Hepatitis; HGF Hepatocyte Growth Factor; LDH - Lobular Dissecting Hepatitis; CIRR - Cirrhosis; ERK1/2 - Mitogen activated protein kinase (MAPK) 1 and 3; hALC - cirrhotic stage of alcoholic liver disease; hHC - cirrhotic stage of chronic hepatitis $\mathrm{C}$ infection; p38-MAPK - Mitogen activated protein kinase (MAPK) 14; PH - Partial Hepatectomy; PKB Protein Kinase B; Q-PCR - Quantitative real-time PCR;
STAT3 - Signal Transducer and Activator of Transcription 3.

\section{Competing interests}

Despite this research was partially funded by the animal health company Intervet International, the authors declare that they have no potential conflict of interests.

\section{Authors' contributions}

BS and BA contributed equally in writing the manuscript. BS performed the Q-PCR measurements. BA performed all Western blot experiments. TI examined the histochemical samples described in this manuscript. TR provided the human liver samples and participated in the study design. JR and LP participated in the study design and coordination of the different experiments. All authors read and approved the final manuscript.

\section{Acknowledgements}

The authors thank Dr. Libbrecht for the (description of) the human samples.

Table 2: Primary Antibodies used in Western blot experiments

\begin{tabular}{|c|c|c|c|}
\hline Antibody & Product size (kDa) & Dilution & Supplier \\
\hline Goat anti-human HGF & 80 & I:I,000 & Santa Cruz \\
\hline Goat anti-human c-MET & 145 & $1: 1,000$ & Santa Cruz \\
\hline Rabbit anti-human c-MET (Tyr | 230/I234/I235) & 169 & $1: 1,000$ & Abcam \\
\hline Rabbit anti-human/dog STAT3 & 86 & $\mathrm{I}: 2,500$ & BD Biosciences \\
\hline Rabbit anti-human phospho-STAT3 (Ser727) & 86 & $1: 1,000$ & Cell Signalling \\
\hline Mouse anti-human phospho-STAT3 (Tyr705) & 86 & I:I,000 & Cell Signalling \\
\hline Mouse anti-human/dog PKB & 60 & $1: 250$ & BD Biosciences \\
\hline Rabbit anti-human phospho-PKB (Thr308) & 60 & I:I,000 & Cell Signalling \\
\hline Rabbit anti-human Erkl/2 & $42 / 44$ & $1: 1,000$ & Cell Signalling \\
\hline Rabbit anti-human phospho-ERKI/2 (Thr202/Tyr204) & $42 / 44$ & I:I,500 & Cell Signalling \\
\hline Rabbit anti-human p38-MAPK & 38 & $1: 500$ & Abcam \\
\hline Rabbit anti-human phospho-p38-MAPK (Thr I80/Tyr I82) & 38 & $1: 1,000$ & Abcam \\
\hline Mouse anti-human/dog Beta-actin (pan Ab-5) & 42 & $\mathrm{I}: 2,000$ & Neomarkers \\
\hline
\end{tabular}




\section{References}

I. Motola-Kuba D, Zamora-Valdes D, Uribe M, Mendez-Sanchez N: Hepatocellular carcinoma. An overview. Ann Hepatol 2006, 5:16-24.

2. Williams R: Global challenges in liver disease. Hepatology 2006, 44:52I-526.

3. Constandinou C, Henderson N, Iredale JP: Modeling liver fibrosis in rodents. Methods $\mathrm{Mol}$ Med 2005, I I 7:237-250.

4. Anstee QM, Goldin RD: Mouse models in non-alcoholic fatty liver disease and steatohepatitis research. Int J Exp Pathol 2006, 87: $1-16$.

5. Belanger M, Butterworth RF: Acute liver failure: a critical appraisal of available animal models. Metab Brain Dis 2005, 20:409-423.

6. Dandri M, Lutgehetmann M, Volz T, Petersen J: Small animal model systems for studying hepatitis $B$ virus replication and pathogenesis. Semin Liver Dis 2006, 26:181-191.

7. Nanji AA, French SW: Animal models of alcoholic liver disease-focus on the intragastric feeding model. Alcohol Res Health 2003, 27:325-330.

8. Siegmund SV, Haas S, Singer MV: Animal models and their results in gastrointestinal alcohol research. Dig Dis 2005, 23: | 8|-194.

9. Ostrander EA, Wayne RK: The canine genome. Genome Res 2005, 15:1706-17|6.

10. Sutter NB, Ostrander EA: Dog star rising: the canine genetic system. Nat Rev Genet 2004, 5:900-910.

II. Spee B, Arends B, van den Ingh TSGAM, Brinkhof B, Nederbragt H, ljzer J, Roskams T, Penning LC, Rothuizen J: Transforming growth factor beta-I signalling in canine hepatic diseases: new models for human fibrotic liver pathologies. Liver Int 2006, 26:716-725.

12. Twedt DC, van den Ingh TSGAM, Charles JA: Standards for Clinical and Histological Diagnosis of Canine and Feline Liver Disease Saunders Elsevier; 2006.

13. Neff MW, Rine J: A fetching model organism. Cell 2006, 1 24:229-23I.

14. Koniaris LG, McKillop IH, Schwartz SI, Zimmers TA: Liver regeneration. J Am Coll Surg 2003, I 97:634-659.

15. Birchmeier C, Birchmeier W, Gherardi E, Vande Woude GF: Met, metastasis, motility and more. Nat Rev Mol Cell Biol 2003, 4:915-925.

16. Hanada M, Feng J, Hemmings BA: Structure, regulation and function of PKB/AKT--a major therapeutic target. Biochim Biophys Acta 2004, 1 697:3-16.

17. Okano J, Shiota G, Matsumoto K, Yasui S, Kurimasa A, Hisatome I, Steinberg $\mathrm{P}$, Murawaki Y: Hepatocyte growth factor exerts a proliferative effect on oval cells through the PI3K/AKT signaling pathway. Biochem Biophys Res Commun 2003, 309:298-304.

18. Bennett AM, Davies JD, Gaskell C), Lucke VM: Lobular dissecting hepatitis in the dog. Vet Pathol I983, 20:179-188.

19. van den Ingh TSGAM, Rothuizen J: Lobular dissecting hepatitis in juvenile and young adult dogs. I Vet Intern Med I994, 8:217-220.

20. Cramer T, Schuppan D, Bauer M, Pfander D, Neuhaus P, Herbst H: Hepatocyte growth factor and c-Met expression in rat and human liver fibrosis. Liver Int 2004, 24:335-344.

21. Hammond DE, Carter S, McCullough J, Urbe S, Vande WG, Clague MJ: Endosomal dynamics of Met determine signaling output. Mol Biol Cell 2003, I 4: I 346-I354.

22. Farinati F, Cardin R, D'Errico A, De MN, Naccarato R, Cecchetto A, Grigioni W: Hepatocyte proliferative activity in chronic liver damage as assessed by the monoclonal antibody MIB I Ki67 in archival material: the role of etiology, disease activity, iron, and lipid peroxidation. Hepatology 1996, 23:|468-|475.

23. Quaglia A, McStay M, Stoeber K, Loddo M, Caplin M, Fanshawe T, Williams G, Dhillon A: Novel markers of cell kinetics to evaluate progression from cirrhosis to hepatocellular carcinoma. Liver Int 2006, 26:424-432.

24. Waris G, Turkson J, Hassanein T, Siddiqui A: Hepatitis C virus (HCV) constitutively activates STAT-3 via oxidative stress: role of STAT-3 in HCV replication. J Virol 2005, 79: I569-I580.

25. Yoshida T, Hanada T, Tokuhisa T, Kosai K, Sata M, Kohara M, Yoshimura A: Activation of STAT3 by the hepatitis $C$ virus core protein leads to cellular transformation. J Exp Med 2002, | 96:64|-653.

26. Starkel P, de Saeger C, Leclercq I, Strain A, Horsmans Y: Deficient Stat3 DNA-binding is associated with high Pias 3 expression and a positive anti-apoptotic balance in human end-stage alcoholic and hepatitis C cirrhosis. J Hepatol 2005, 43:687-695.

27. Giambartolomei S, Covone F, Levrero M, Balsano C: Sustained activation of the Raf/MEK/Erk pathway in response to EGF in stable cell lines expressing the Hepatitis C Virus (HCV) core protein. Oncogene 200I, 20:2606-2610.

28. Furukawa F, Matsuzaki K, Mori S, Tahashi Y, Yoshida K, Sugano Y, Yamagata H, Matsushita M, Seki T, Inagaki Y, Nishizawa M, Fujisawa J, Inoue K: p38 MAPK mediates fibrogenic signal through Smad3 phosphorylation in rat myofibroblasts. Hepatology 2003, 38:879-889.

29. Gupta S, Rajvanshi P, Aragona E, Lee CD, Yerneni PR, Burk RD: Transplanted hepatocytes proliferate differently after $\mathrm{CCl} 4$ treatment and hepatocyte growth factor infusion. Am J Physiol 1999, 276:G629-G638.

30. Kosai K, Matsumoto K, Funakoshi H, Nakamura T: Hepatocyte growth factor prevents endotoxin-induced lethal hepatic failure in mice. Hepatology 1999, 30:151-159.

31. Matsuda Y, Matsumoto K, Yamada A, Ichida T, Asakura H, Komoriya $Y$, Nishiyama E, Nakamura T: Preventive and therapeutic effects in rats of hepatocyte growth factor infusion on liver fibrosis/ cirrhosis. Hepatology 1997, 26:81-89.

32. Palmes D, Spiegel HU: Animal models of liver regeneration. Biomaterials 2004, 25: I60I-I6II.

33. Corrao G, Zambon A, Torchio P, Arico S, La Vecchia C, di Orio F: Attributable risk for symptomatic liver cirrhosis in Italy. Collaborative Groups for the Study of Liver Diseases in Italy. J Hepatol 1998, 28:608-6|4.

34. Morgan G: Beneficial effects of NSAIDs in the gastrointestinal tract. Eur J Gastroenterol Hepatol 1999, I I:393-400.

35. Jalan R, Hayes PC: Hepatic encephalopathy and ascites. Lancet 1997, 350:1309-|3|5.

36. Boomkens SY, Penning LC, Egberink HF, van den Ingh TSGAM, Rothuizen J: Hepatitis with special reference to dogs. A review on the pathogenesis and infectious etiologies, including unpublished results of recent own studies. Vet $Q 2004$, 26:107-114.

37. Spee B, Mandigers PJ, Arends B, Bode P, van den Ingh TSGAM, Hoffmann G, Rothuizen J, Penning LC: Differential expression of copper-associated and oxidative stress related proteins in a new variant of copper toxicosis in Doberman pinschers. Comp Hepatol 2005, 4:3

38. Brinkhof B, Spee B, Rothuizen J, Penning LC: Development and evaluation of canine reference genes for accurate quantification of gene expression. Anal Biochem 2006, 356:36-43.

39. Spee B, Penning LC, van den Ingh TSGAM, Arends B, ljzer J, van Sluijs F], Rothuizen J: Regenerative and fibrotic pathways in canine hepatic portosystemic shunt and portal vein hypoplasia, new models for clinical hepatocyte growth factor treatment. Comp Hepatol 2005, 4:7.

Publish with BioMed Central and every scientist can read your work free of charge

"BioMed Central will be the most significant development for disseminating the results of biomedical research in our lifetime. "

Sir Paul Nurse, Cancer Research UK

Your research papers will be:

- available free of charge to the entire biomedical community

- peer reviewed and published immediately upon acceptance

- cited in PubMed and archived on PubMed Central

- yours - you keep the copyright
BioMedcentral 